\title{
Biological Mediator-Propelled Nanosweeper for Nonpharmaceutical Thrombus Therapy
}

Qingqing Deng, ${ }^{1,2}$ Lu Zhang, ${ }^{1,3}$ Wei Lv, ${ }^{4}$ Xuemeng Liu, ${ }^{1,2}$ Jinsong Ren *1,2,3 and Xiaogang $Q u^{*, 1,2,3}$

${ }^{1}$ Laboratory of Chemical Biology and State Key Laboratory of Rare Earth Resource Utilization, Changchun Institute of Applied Chemistry, Chinese Academy of Sciences, Changchun, Jilin 130022, China.

E-mail: jren@ciac.ac.cn (Jinsong Ren), xqu@ciac.ac.cn (Xiaogang Qu)

${ }^{2}$ University of Science and Technology of China, Hefei, Anhui 230026, China.

${ }^{3}$ University of Chinese Academy of Sciences, Beijing 100039, China

${ }^{4}$ Department of Oncology, Second Affiliated Hospital of Xi'an Jiaotong University, Xi'an 710004, China 


\section{Materials}

Dopamine hydrochloride, $N, N^{\prime}$-bis-sec-butylamino-p-phenylenediamine (BPA), pluronic F127 (PF127), and 1,3,5-trimethyl benzene (TMB), and were purchased from Aladdin. Ammonia solution (25\%-28\%) and ethanol were obtained from Beijing chemical works. Kappa-carrageenan and $\mathrm{NaNO}_{2}$ were purchased Macklin. CREKA (Cys-Arg-Glu-Lys-Ala) peptide was obtained from Shanghai Sangon Biological Engineering Technology and Services. All chemicals were used without further purification.

\section{Synthesis of BNN6}

$N, N^{\prime}$-di-sec-butyl- $N, N^{\prime}$-dinitroso-1,4-phenylenediamine (BNN6) was synthesized according to the previous report. $2.34 \mathrm{~mL}$ BPA was diluted into $18 \mathrm{~mL}$ ethanol, and then mixed with $\mathrm{NaNO}_{2}$ solution $(20 \mathrm{~mL} 6 \mathrm{M})$ under stirring and under nitrogen protection. After $30 \mathrm{~min}$, the $\mathrm{HCl}$ solution (20 mL $6 \mathrm{M})$ was added dropwise. After stirring for $4 \mathrm{~h}$, the beige solid product was collected by centrifugation and dried under a freezing vacuum overnight.

\section{Photothermal conversion efficiency of B@P@C}

To evaluate the photothermal conversion efficiency, the B@P@C solution $(100 \mu \mathrm{g} / \mathrm{mL}, 0.5 \mathrm{~mL})$ was heated to a steady temperature with an $808 \mathrm{~nm}$ laser at a power density of $1 \mathrm{~W} / \mathrm{cm}^{2}$ and then 
naturally cooled. The photothermal conversion efficiency was calculated according to the previous literature.

$\eta=\frac{h s\left(T_{\max }-T_{\min }\right)-Q_{d i s}}{I\left(1-10^{-A}\right)} * 100 \%$

where $h$ represents the heat transfer coefficient of B@P@C and $S$ represents the surface area of the container used, $T_{\max }$ represents the maximum temperature of the whole process and $T_{\min }$ represents the room temperature, $Q_{d i s}$ represents the heat dissipation of the water, $I$ is the laser intensity employed $\left(1 \mathrm{~W} / \mathrm{cm}^{2}\right)$, and $A$ is the absorbance of $\mathrm{B} @ \mathrm{P} @ \mathrm{C}$ at $808 \mathrm{~nm}(0.1998)$. Moreover, the result of hs is calculated according to the following equation

$\tau_{s}=\frac{m_{D} c_{D}}{h s}$

The $m_{D}$ is the mass $(500 \mathrm{mg})$ and $c_{D}$ is heat capacity $(4.2 \mathrm{~J} / \mathrm{g})$ of the milliQ water used to disperse the B@P@C. Where the $\tau_{s}$ represents the time constant for heat transfer of the solution, which was calculated according to the following equation:

$$
\begin{aligned}
& \tau_{s}=-\frac{t}{\operatorname{Ln} \theta} \\
& \theta=\frac{T_{a m b}-T}{T_{a m b}-T_{\max }}
\end{aligned}
$$

$\theta$ is the dimensionless driving force temperature, and the $T_{a m b}$ is the ambient temperature. The $\tau_{s}$ was determined to be 270.5 , thus, the $h s$ was calculated to be $0.00776 \mathrm{~W}$. $Q_{d i s}$ is the heat dissipation from the laser power absorbed by milliQ water, so $Q_{d i s}$ was obtained according to the 
following equation:

$$
Q_{\text {dis }}=\frac{C_{D} m_{D}\left(T_{\max (\text { water })}-T_{\mathrm{amb}}\right)}{\tau_{S(\text { water })}}
$$

where $T_{\max (\text { water) }}$ is the maximum temperature of water after laser irradiation and $\tau_{s(\text { water })}$ is 122.09 s; thus, $Q_{\text {dis }}$ was calculated to be $0.0378 \mathrm{~W}$. According to the obtained data and equation (1), the photothermal conversion efficiency of B@P@C was calculated to be 48.7\%.

\section{Cytotoxicity Assays and in vivo Biosafety}

After growing in 96-well plates for $24 \mathrm{~h}$, the raw and HUVEC cells were incubated with different concentrations of B@P@C for another 24 h. $20 \mu \mathrm{L}$ of MTT solution $(5 \mathrm{mg} / \mathrm{mL}$ in PBS) was added to each well and further incubated at $37{ }^{\circ} \mathrm{C}$ for $4 \mathrm{~h}$. Then the supernatant was removed and $150 \mu \mathrm{L}$ of dimethyl sulfoxide was added. The cell viability was determined by measuring the absorbance at $490 \mathrm{~nm}$ after several times of shaking.

Saline or B@P@C at an applied concentration was directly intravenous injected into the healthy mice. After 28 days, the mice were sacrificed, and the major organs of mice were harvested. Histological analysis was used to evaluate the biosafety of our materials. The blood was used to carry out serum biochemistry assay and complete blood panel analysis.

For hemolysis test, $1 \mathrm{~mL}$ whole blood was collected in tubes containing Li-heparin from the orbital venous of Kunming mice. Then, $1 \mathrm{~mL}$ blood was mixed with $10 \mathrm{~mL}$ PBS (10mM), followed by centrifuge $5 \mathrm{~min}$ at $2500 \mathrm{rpm}$ and remove the supernatant, and and this is repeated 
3-4 times until the supernatant becoming colorless transparent. The precipitated erythrocytes were then dispersed in $1 \times \mathrm{PBS}$ to get erythrocyte suspension. The $\mathrm{B} @ \mathrm{P} @ \mathrm{C}$ were added to the erythrocyte suspension to a final concentration of $20,40,60,80,100 \mu \mathrm{g} / \mathrm{mL}$. The negative control was placed with erythrocyte suspension diluted with $1 \times \mathrm{PBS}$, the positive control was placed with erythrocyte suspension diluted with ultrapure water. The tubes were incubated for 8 $\mathrm{h}$ at room temperature, observe and record the hemolysis phenomenon. At the meanwhile, the specific $540 \mathrm{~nm}$ spectrophotometric absorptions of hemoglobin were analyzed. Calculation the hemolysis rate (HR \%) by the following equation:

$\mathrm{HR} \%=(\mathrm{B} @ \mathrm{P} @ \mathrm{C}-$ negative $) \times($ positive -negative $) * 100 \%$

\section{The Determination of Thrombogenicity and Blood Coagulation Factor}

The mouse blood was collected into vacuum-tubes, mixed with $1 / 10$ citrate $0.105 \mathrm{M}$ and centrifuged at $3000 \times \mathrm{g}$ for $20 \mathrm{~min}$. Plasma was harvested, snap frozen and stored at $-80{ }^{\circ} \mathrm{C}$ for measured the thrombogenicity: prothrombin time (PT), activated partial thromboplastin time (APTT), thrombin time (TT) and fibrinogen (FIB). The coagulant factors (Fxa), anticoagulant factors (AT-III) and fibrinolytic factor (t-PA) were mesure by the enzyme-linked immunosorbent assay. 
Supplementary Figures 


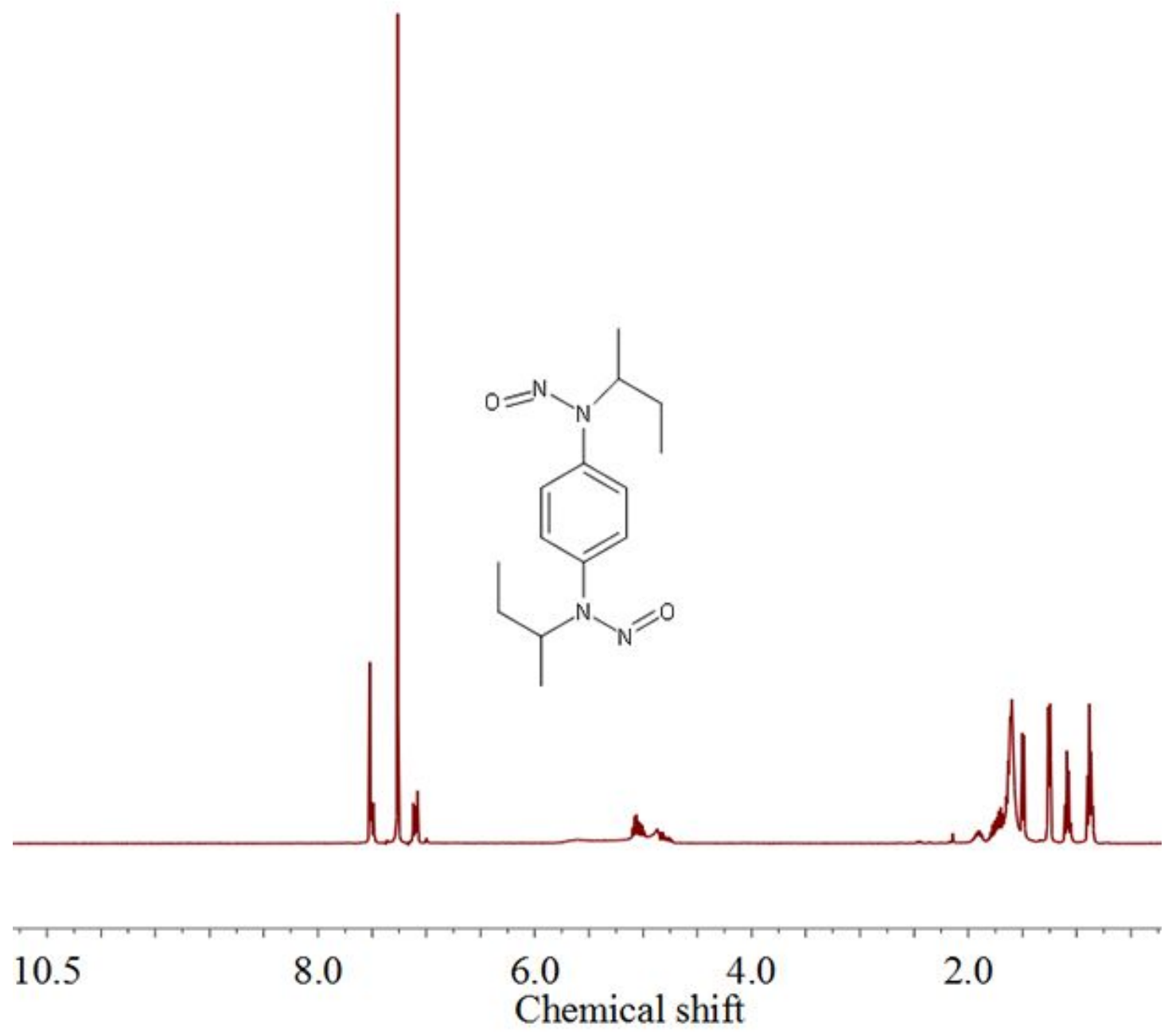

Figure S1. ${ }^{1} \mathrm{H}$ NMR spectra of BNN6 (400 MHz, $\left.\mathrm{CDCl}_{3}\right) \delta 7.52(4 \mathrm{H}), 4.95-4.69(2 \mathrm{H}), 2.00-1.84$ $(2 \mathrm{H}), 1.81-1.69(2 \mathrm{H}), 1.48(\mathrm{t}, \mathrm{J}=7.6 \mathrm{~Hz}, 6 \mathrm{H}), 1.08(\mathrm{td}, \mathrm{J}=7.4,5.3 \mathrm{~Hz}, 6 \mathrm{H})$. 


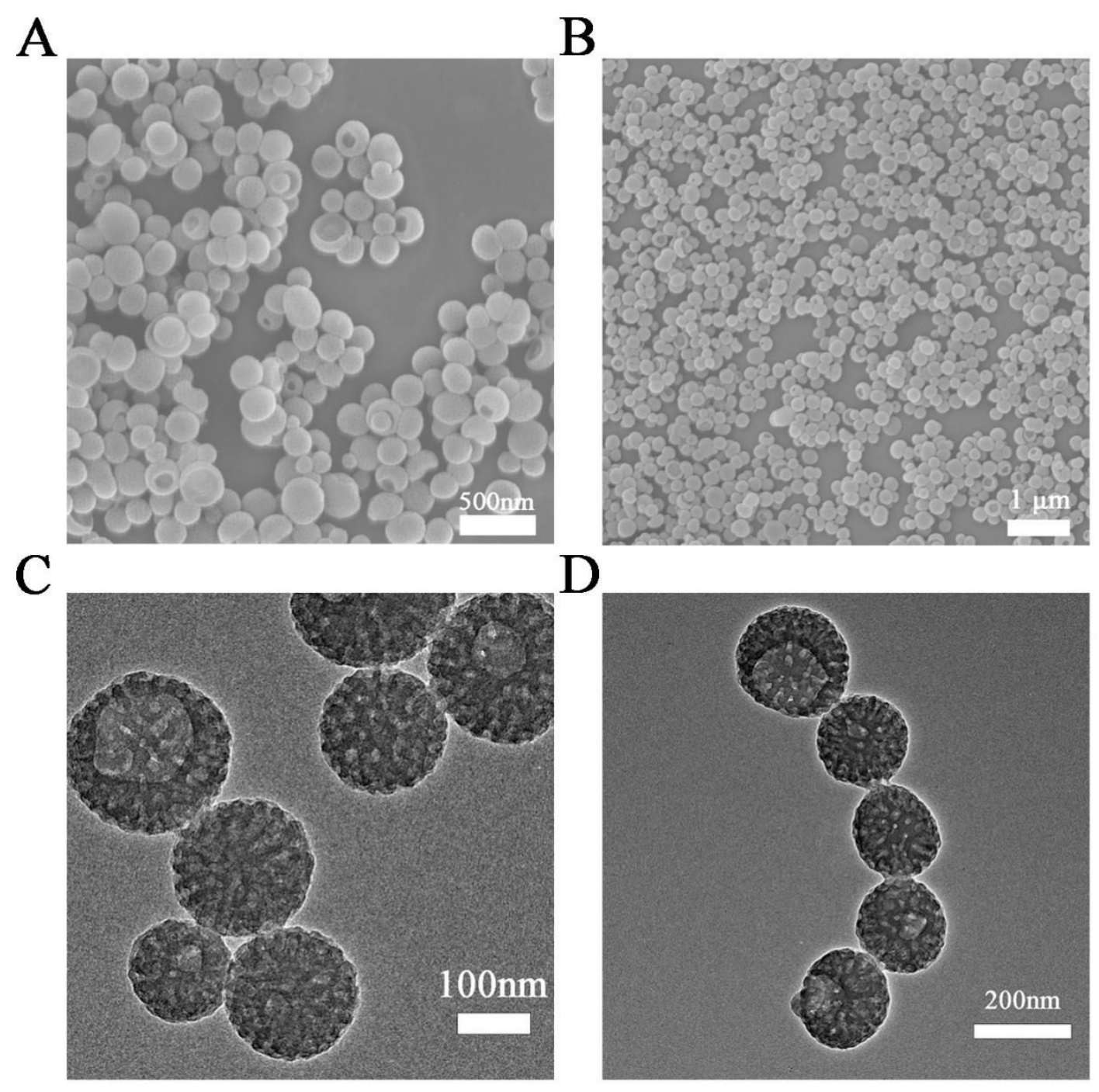

Figure S2. SEM images of (A) PDA. (B) B@P. TEM images of (C) PDA. (D) B@P. 


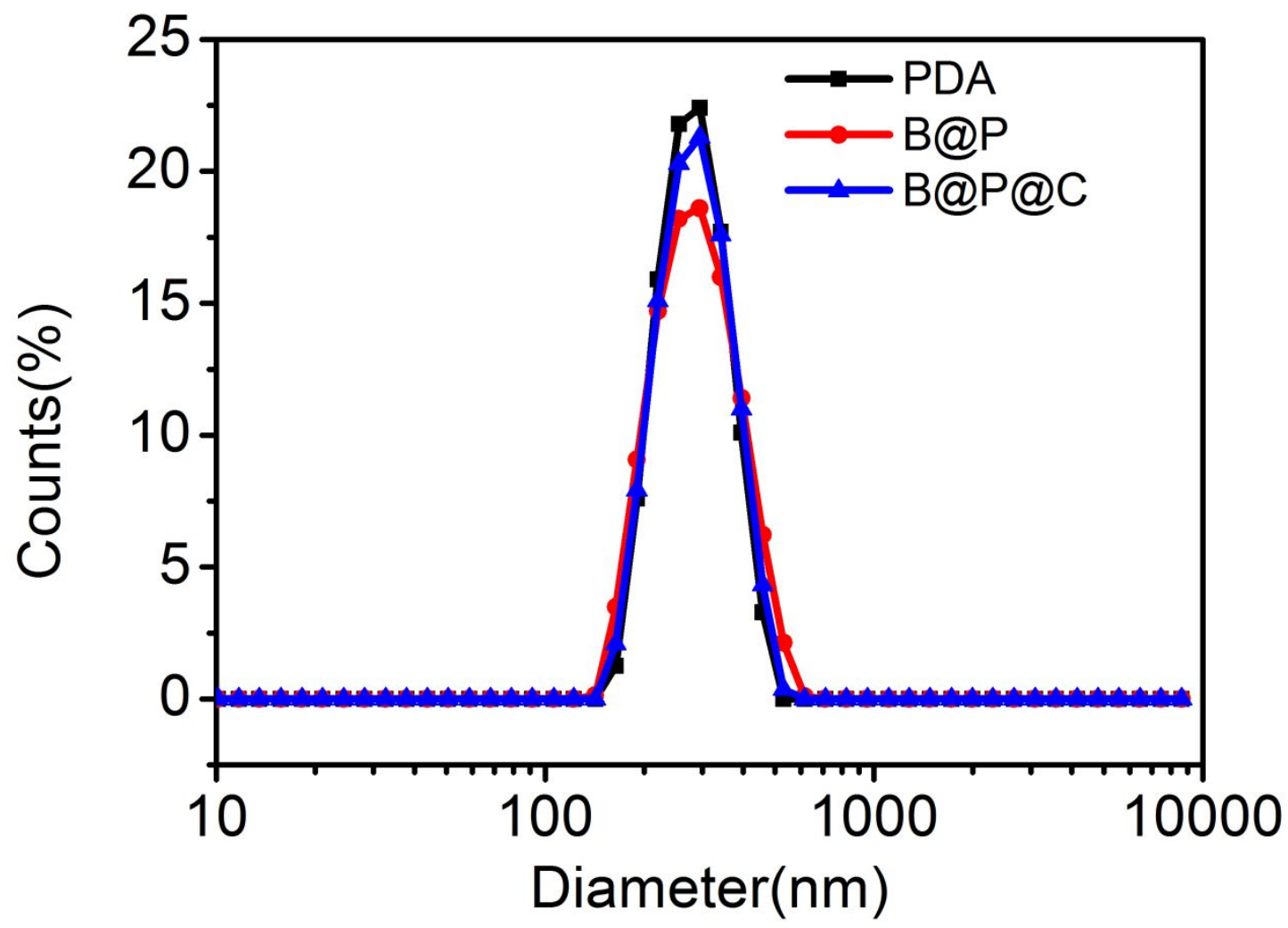

Figure S3. The size distribution histogram of PDA, B@P, and B@P@C. 

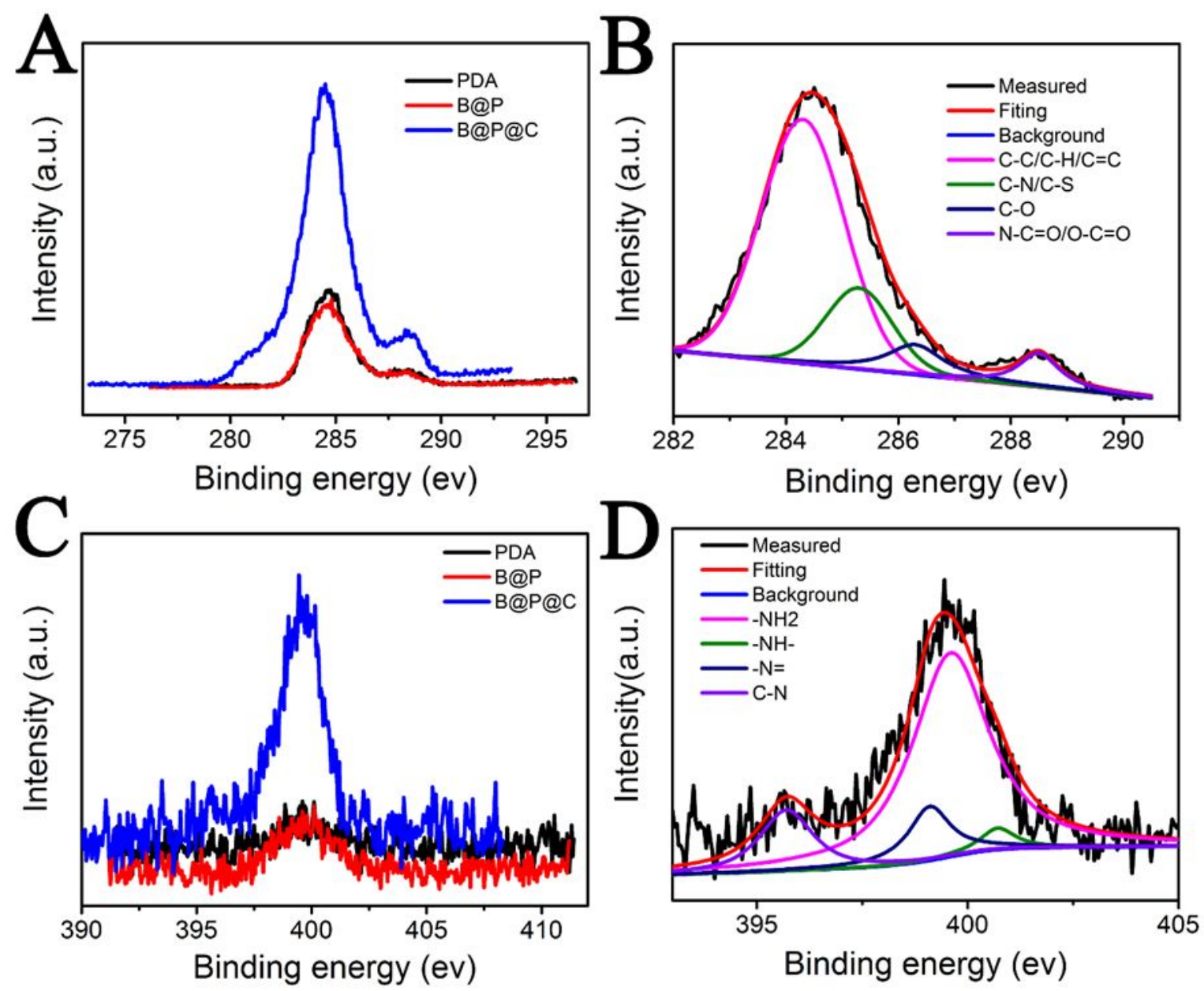

Figure S4. XPS analysis of (A) C 1s of PDA, B@P, and B@P@C, (B) C 1s of 2p of B@P@C (C) N 1s of PDA, B@P, and B@P@C, (D) N 1s of 2p of B@P@C. 


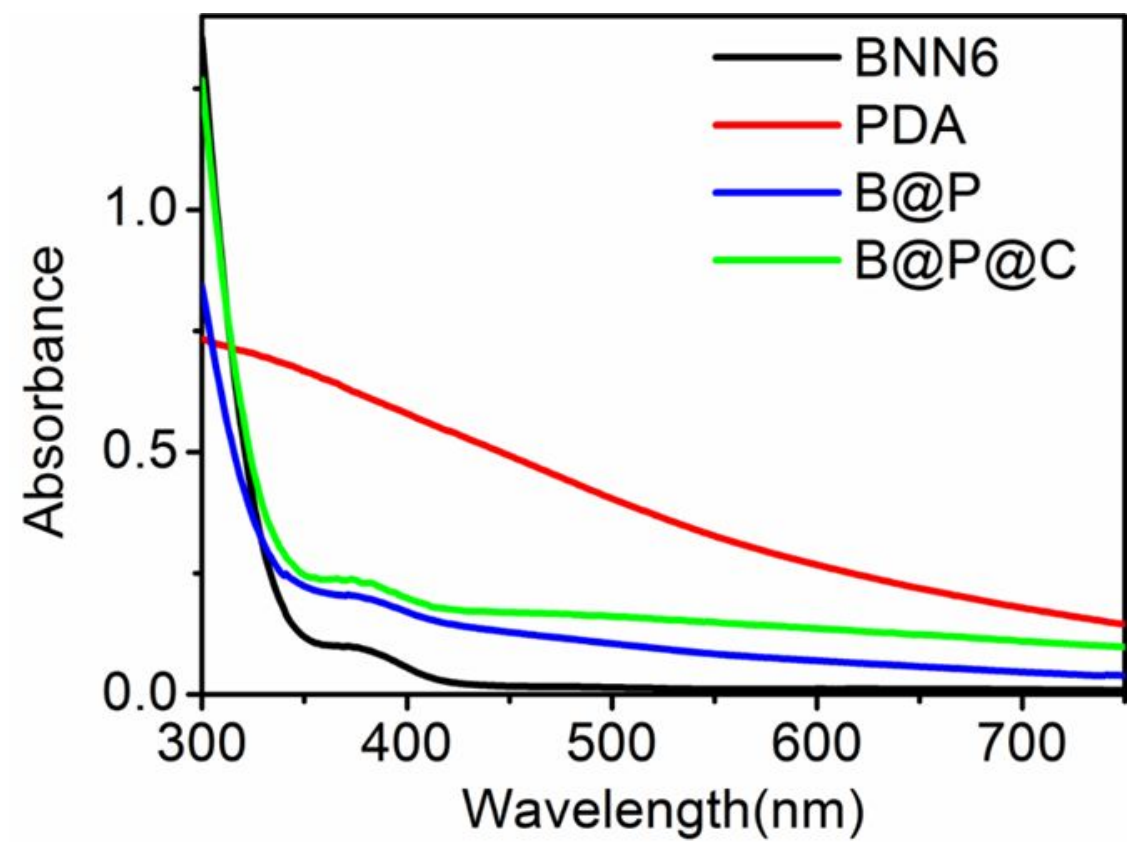

Figure S5. UV-vis spectra of BNN6, PDA, B@P, and B@P@C. 


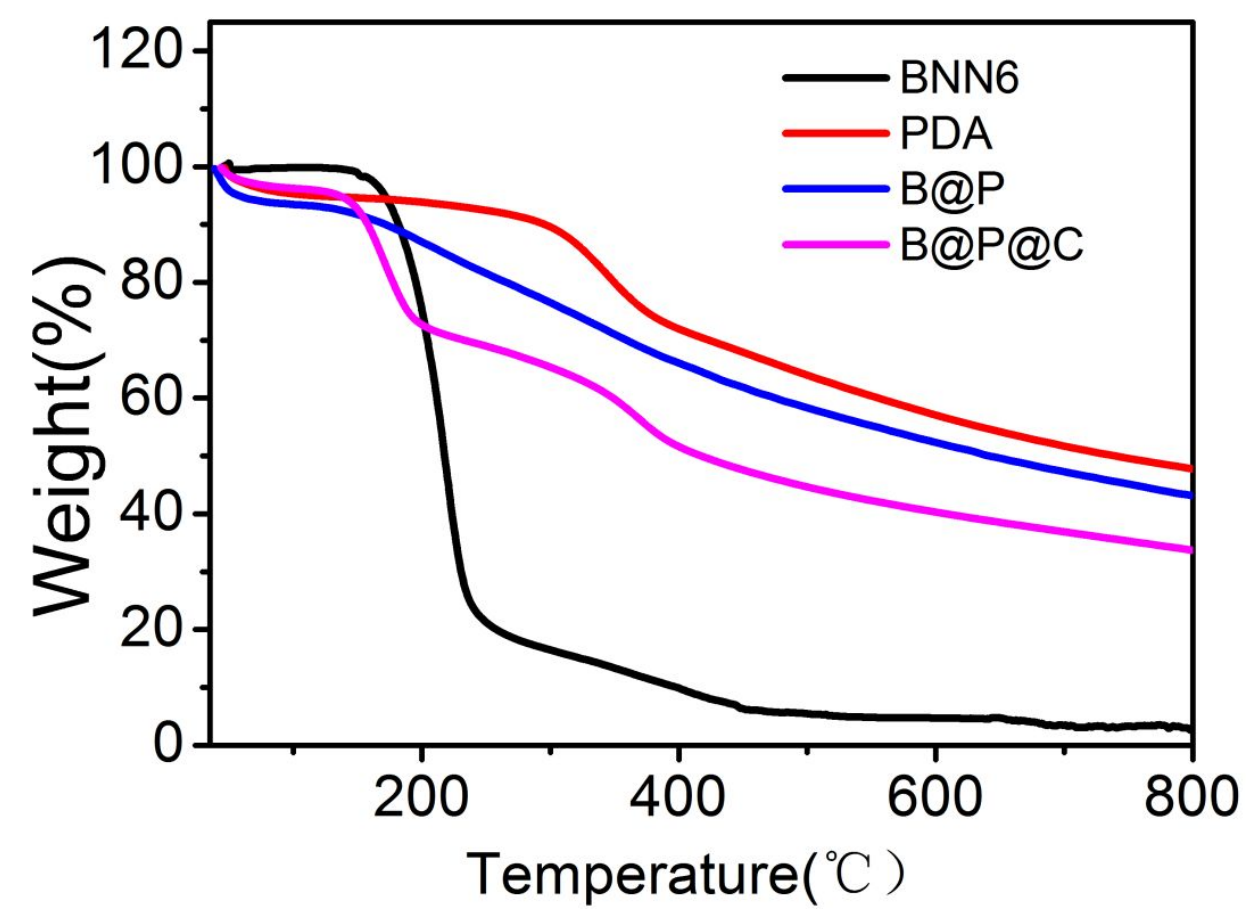

Figure S6. Thermogravimetric analysis (TGA) curves of the PDA, B@P, and $\mathrm{B} @ \mathrm{P} @ \mathrm{C}$. 

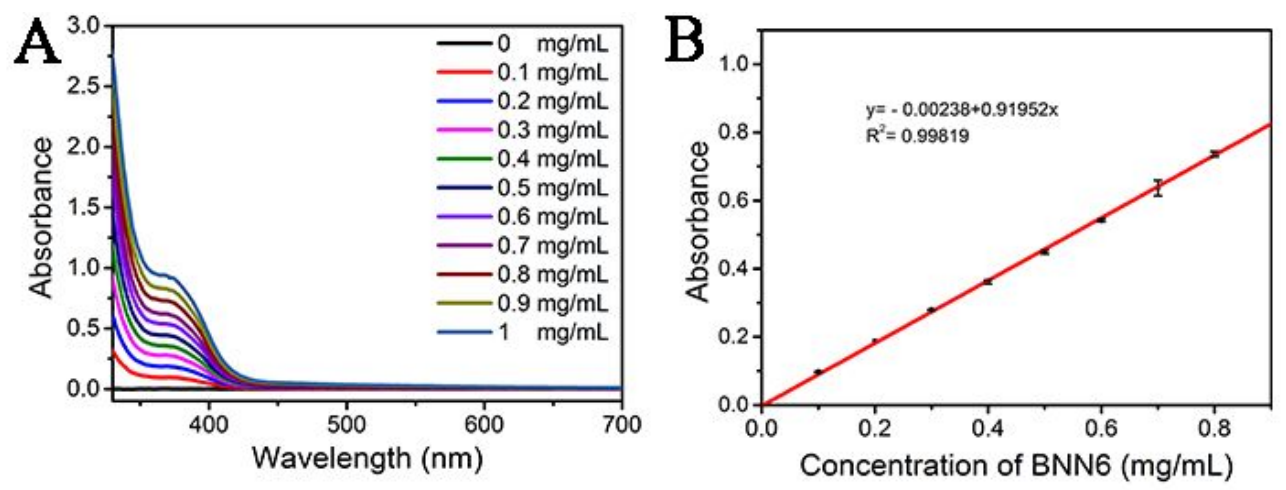

Figure S7. The calibration curve of absorbance at $367 \mathrm{~nm}$ and the concentration of BNN6. 


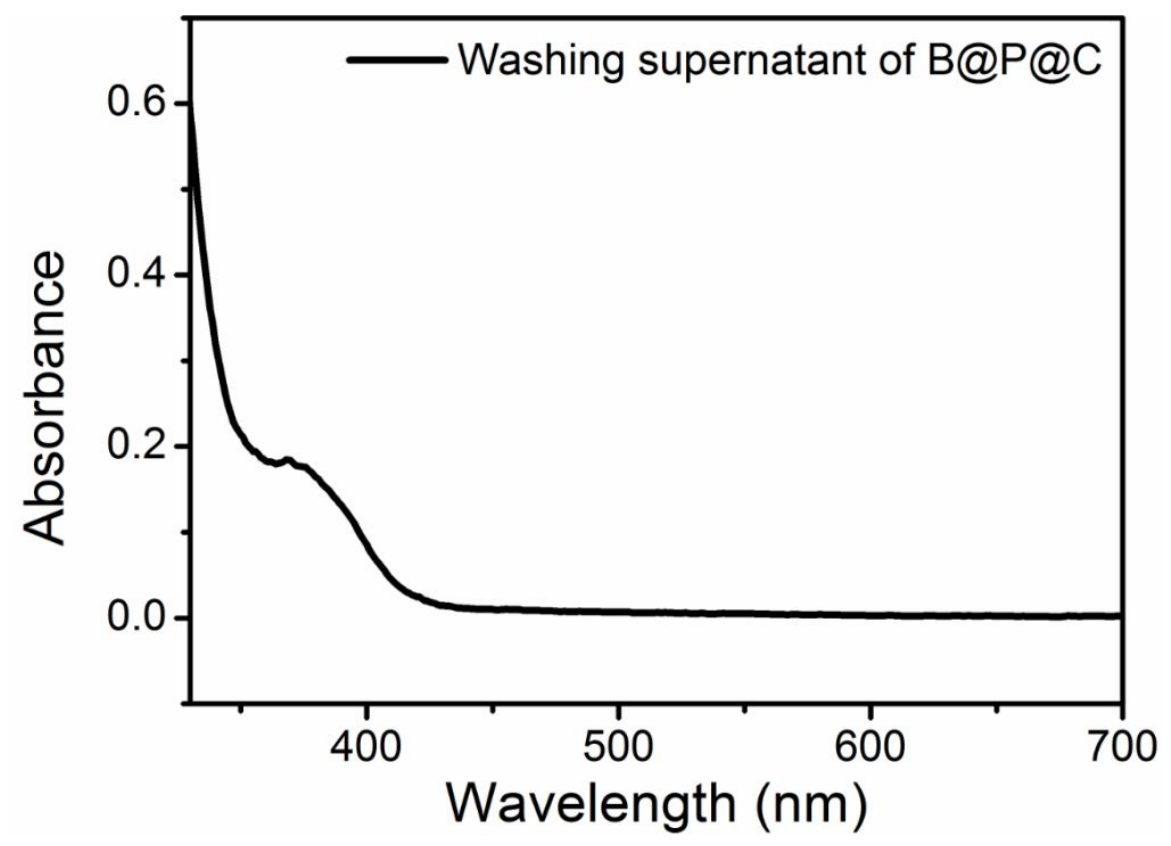

Figure S8. The UV-vis spectra of wash supernatant of B@P@C. 


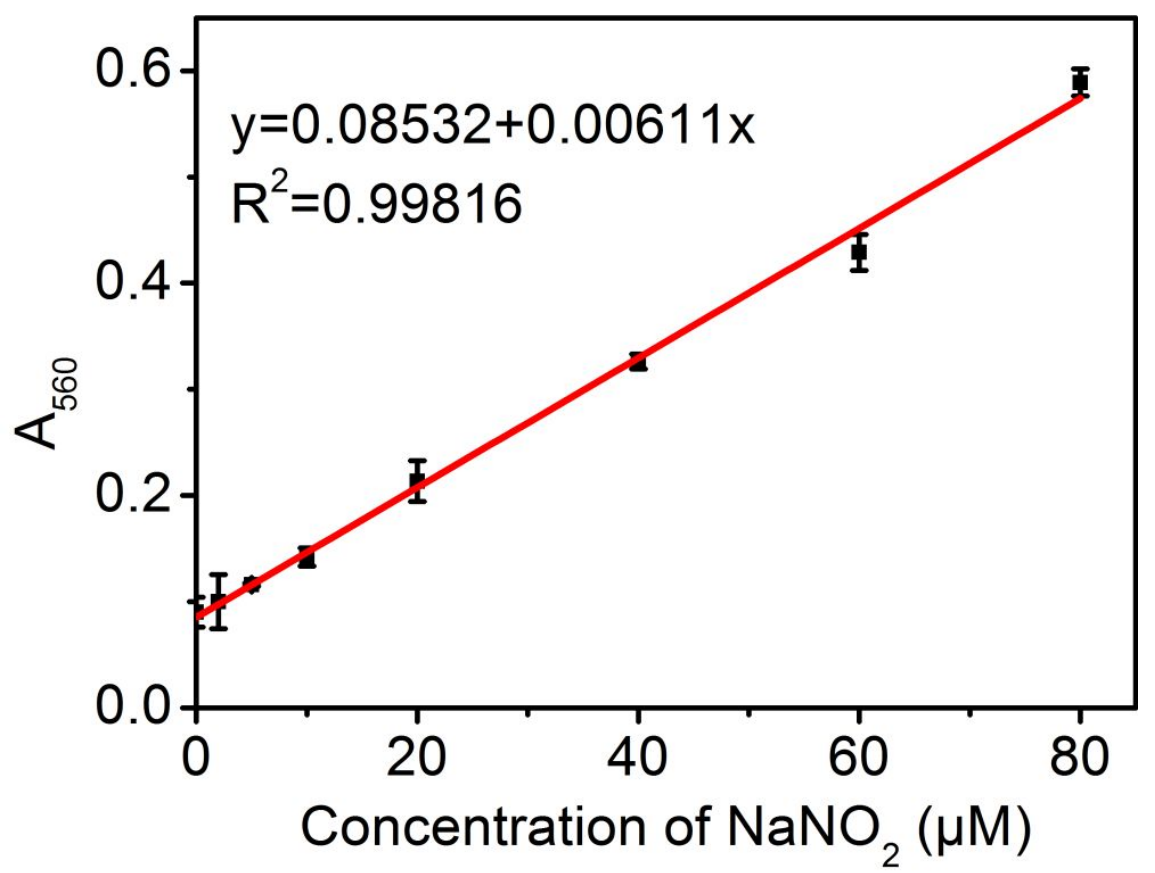

Figure S9. The calibration curve of absorbance at $540 \mathrm{~nm}$ and the concentration of $\mathrm{NaNO}_{2}$. 


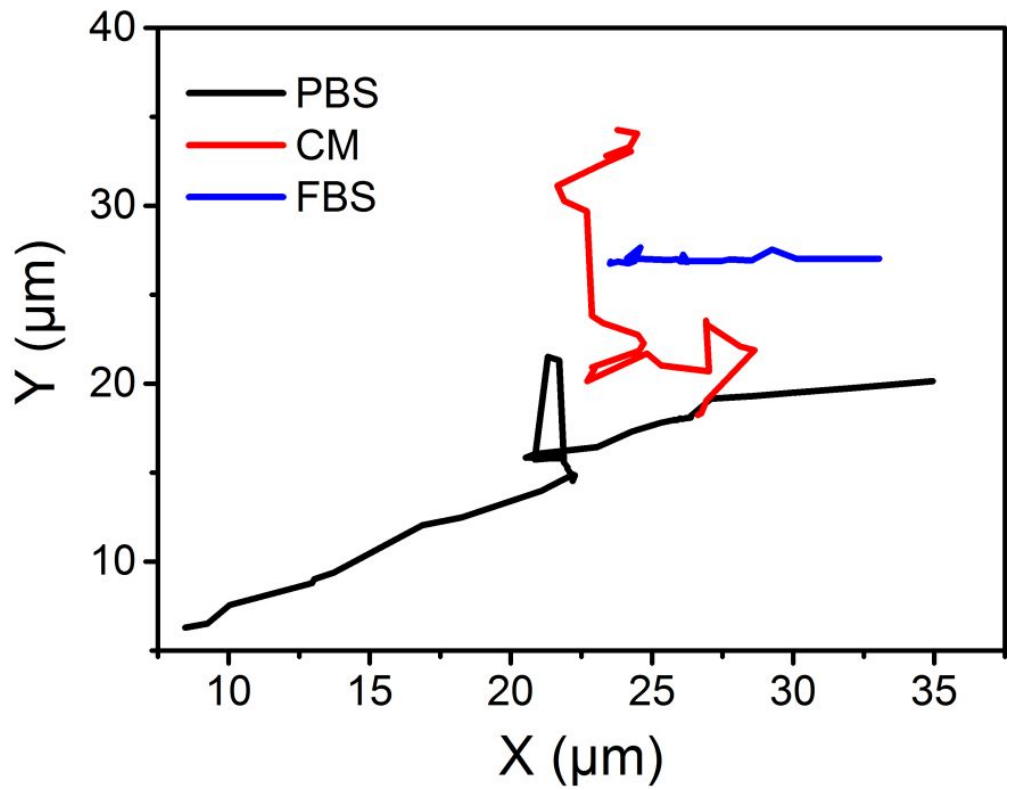

Figure S10. The voyage trajectories of B@P@C nanosweepers in different solution. 


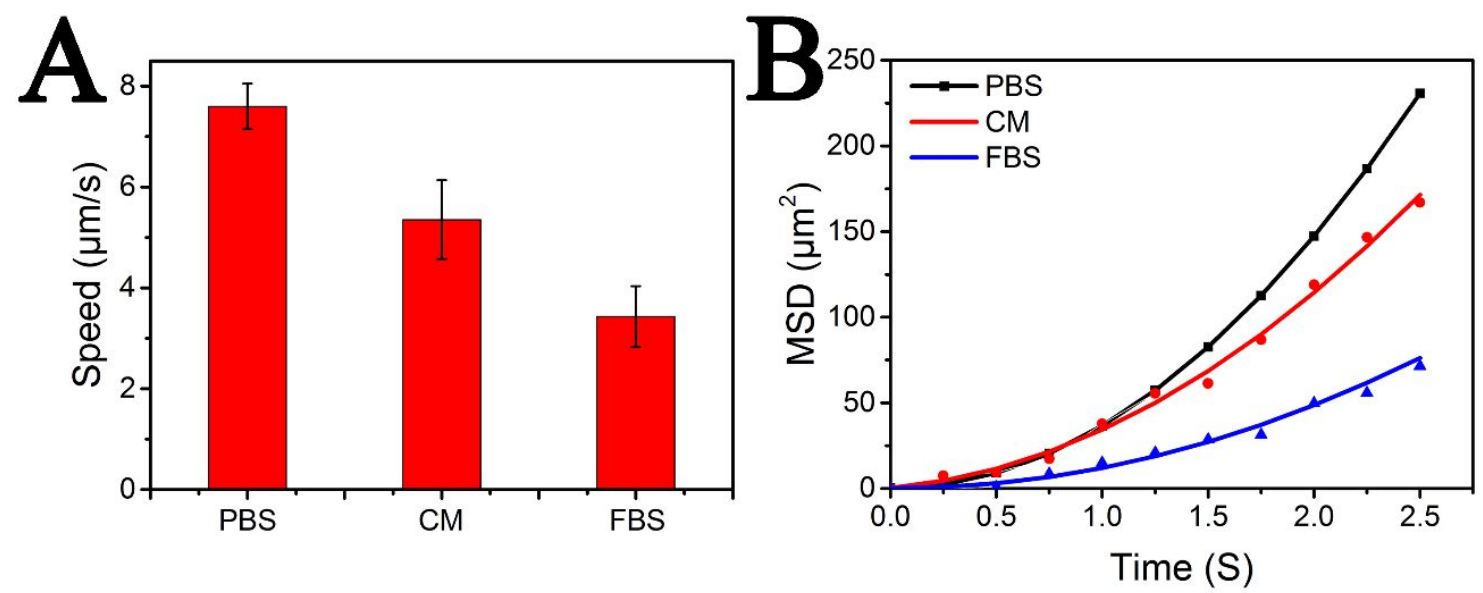

Figure S11. The Speed of B@P@C nanosweepers in different solution. 


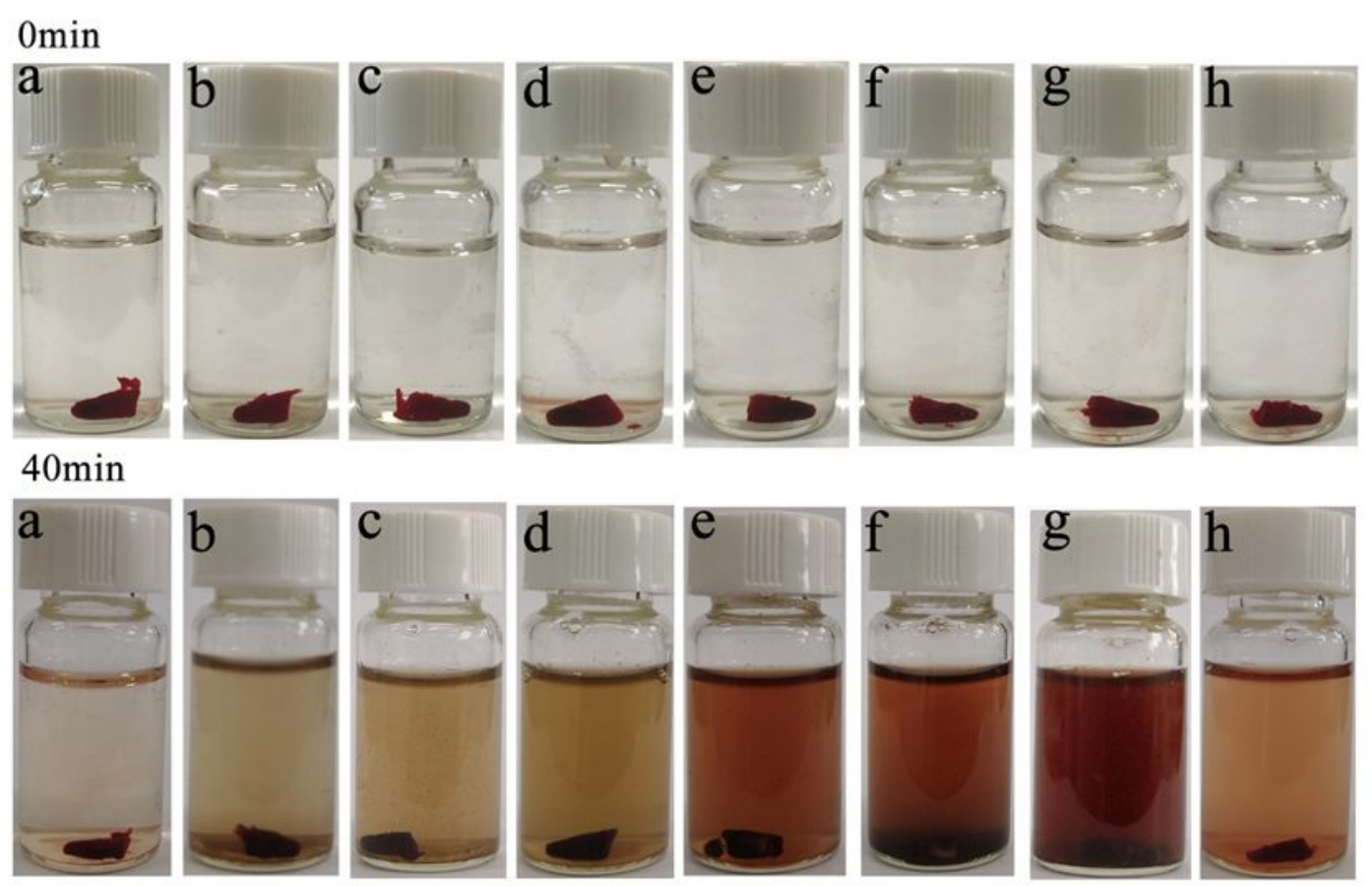

Figure S12. Photos of blood clots before and after different treatments: (a) PBS, (b) PDA, (c) B@P, (d) B@P@C, (e) PDA+L, (f) B@P+L, (g) B@P@C+L and (h) uPA. 


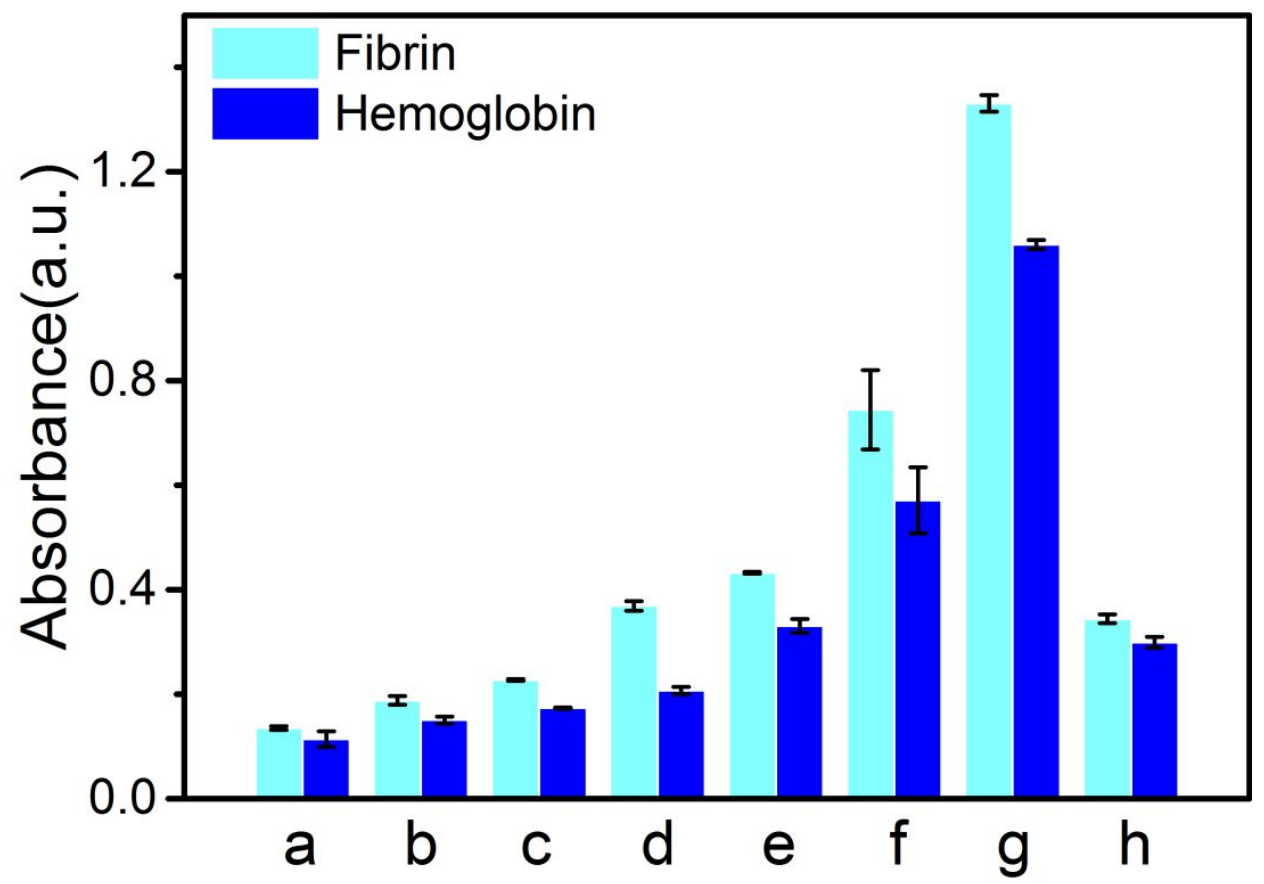

Figure S13. Level of fibrin and hemoglobin in artificial blood clot supernatant after different treatment: (a) PBS, (b) PDA, (c) B@P, (d) B@P@C, (e) PDA+L, (f) B@P+L, (g) B@P@C+L and (h) uPA. 


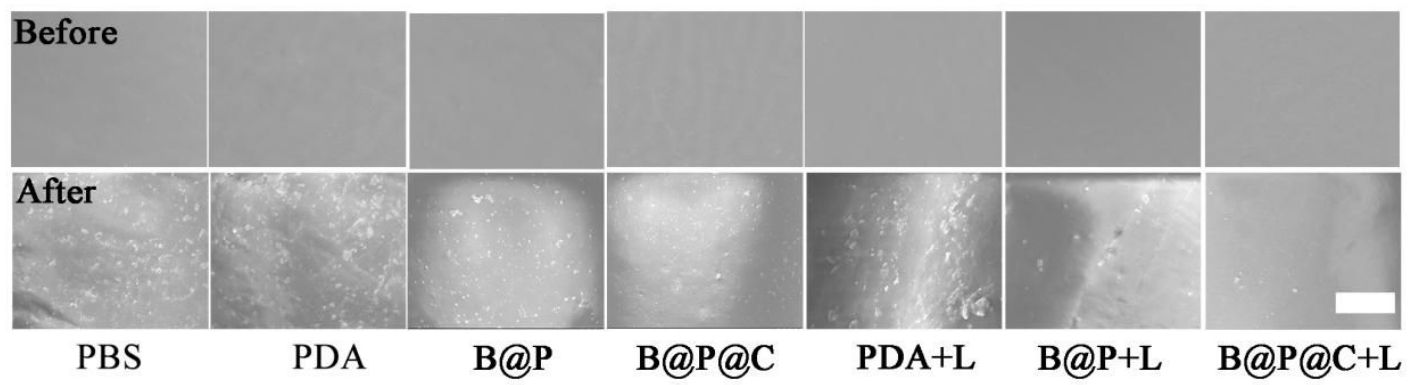

Figure S14. SEM images of PBS, PDA, B@P, B@P@C, PDA+L, B@P+L, and B@P@C+L-embed films before and after incubated with platelet-rich mouse blood plasma (Scale bar: $20 \mu \mathrm{m}$ ). 


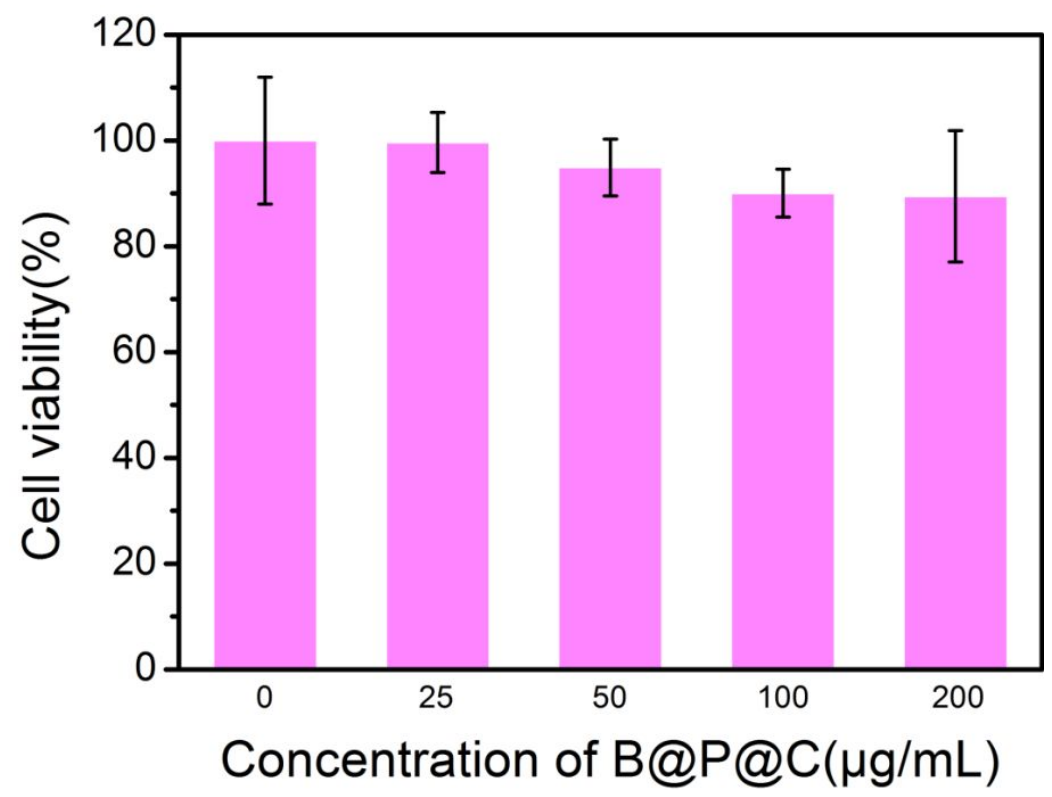

Figure S15. Cytotoxicity studies by MTT assay for RAW cells after incubation with various concentrations of B@P@C for 24 h. Data were presented as mean \pm s.d. $(\mathrm{n}=5)$ 


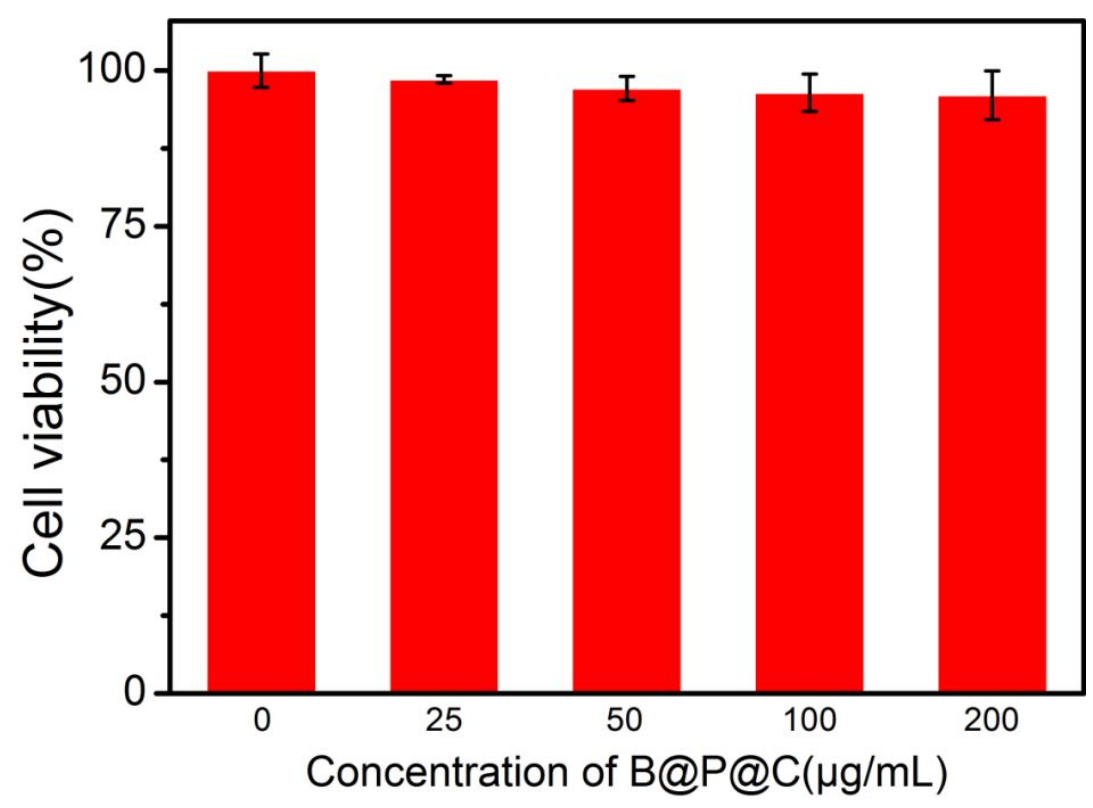

Figure S16. Cytotoxicity studies by MTT assay for HUVEC cells after incubation with various concentrations of B@P@C for 24 h. Data were presented as mean \pm s.d. $(\mathrm{n}=5)$ 


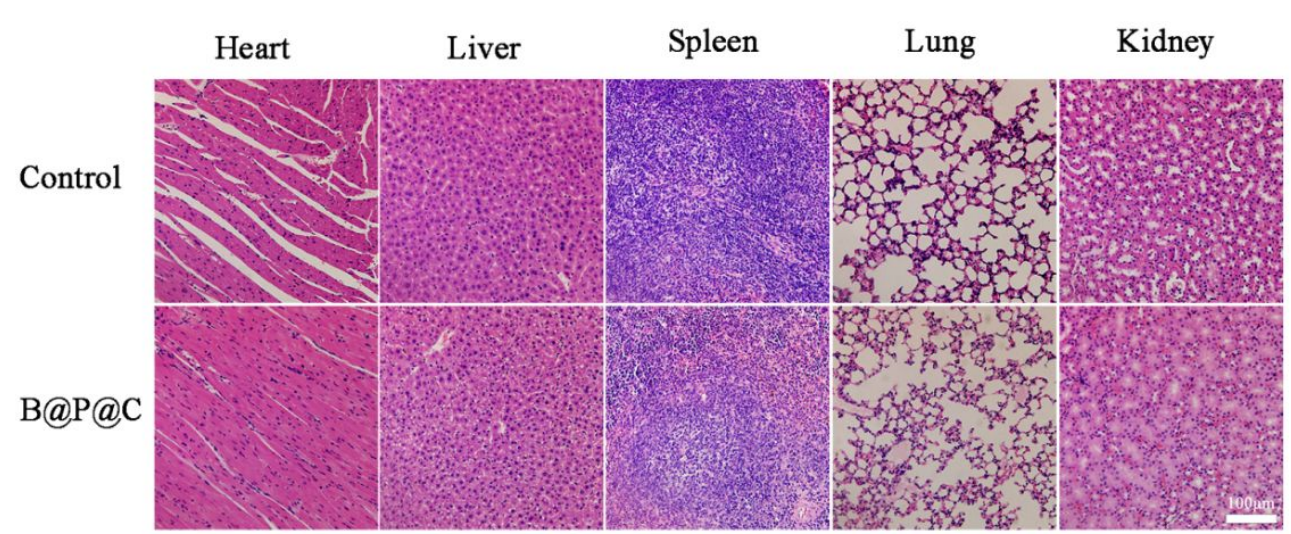

Figure S17. H\&E staining assays of the major organs from all experimental groups. The scale bar was $100 \mu \mathrm{m}$. 

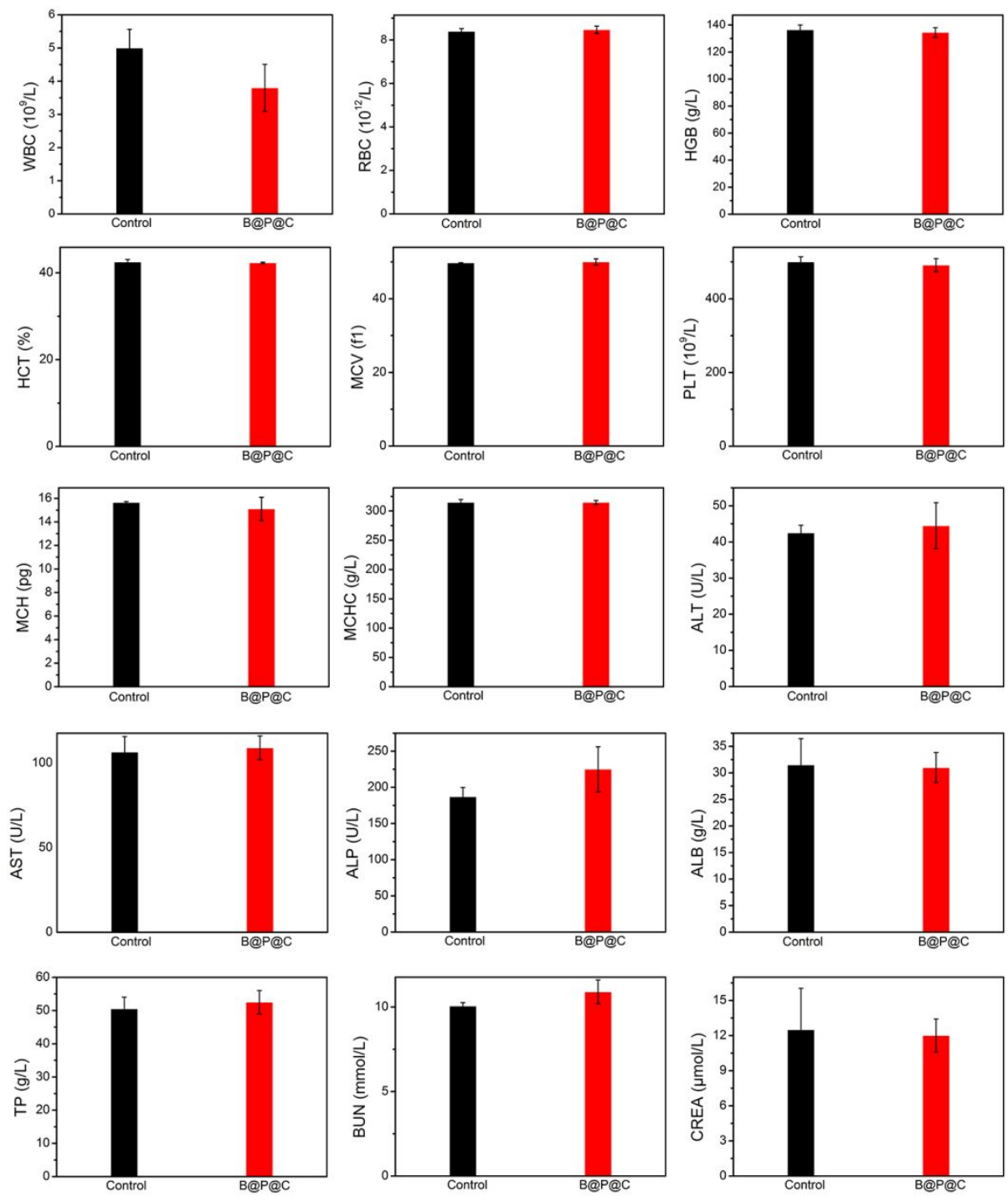

Figure S18. Blood biochemical levels and hematological parameters of the mice after treatment with B@P@C or PBS for 28 days. 


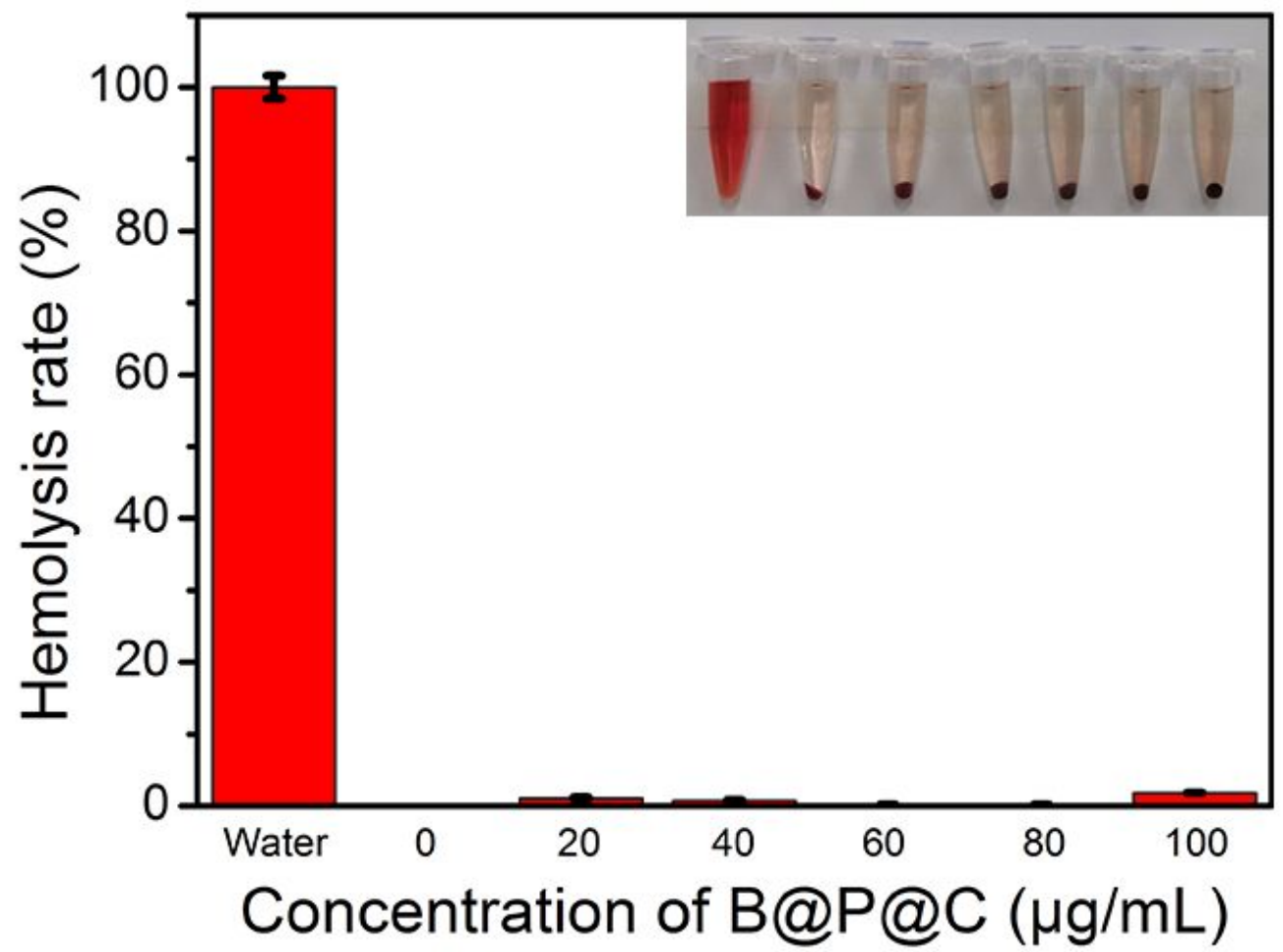

Figure S19. Hemolysis rate of B@P@C. 


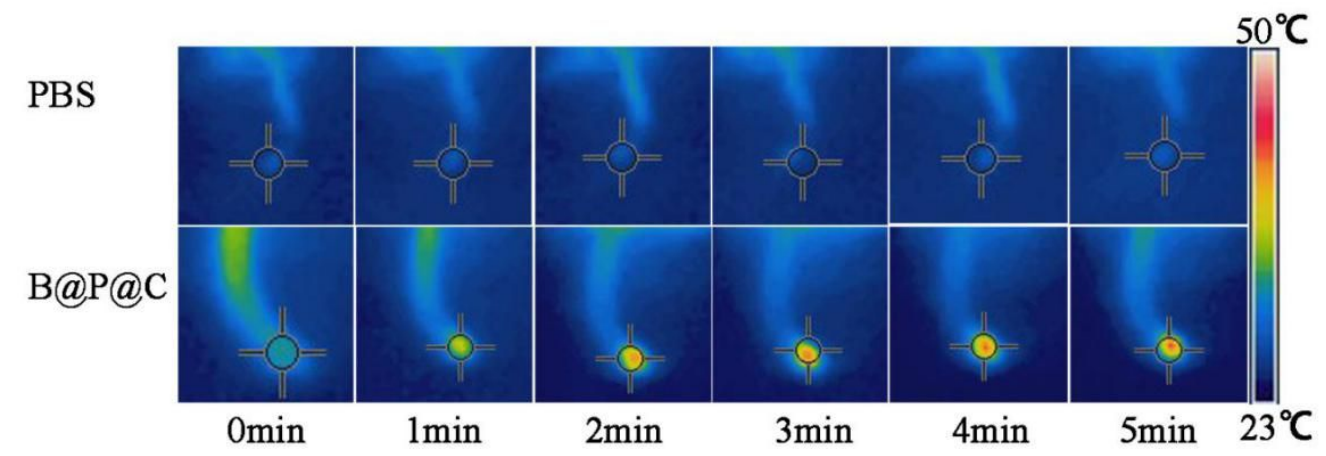

Figure S20. IR images of the black tail of mice with different treatments and irradiation with NIR laser. 


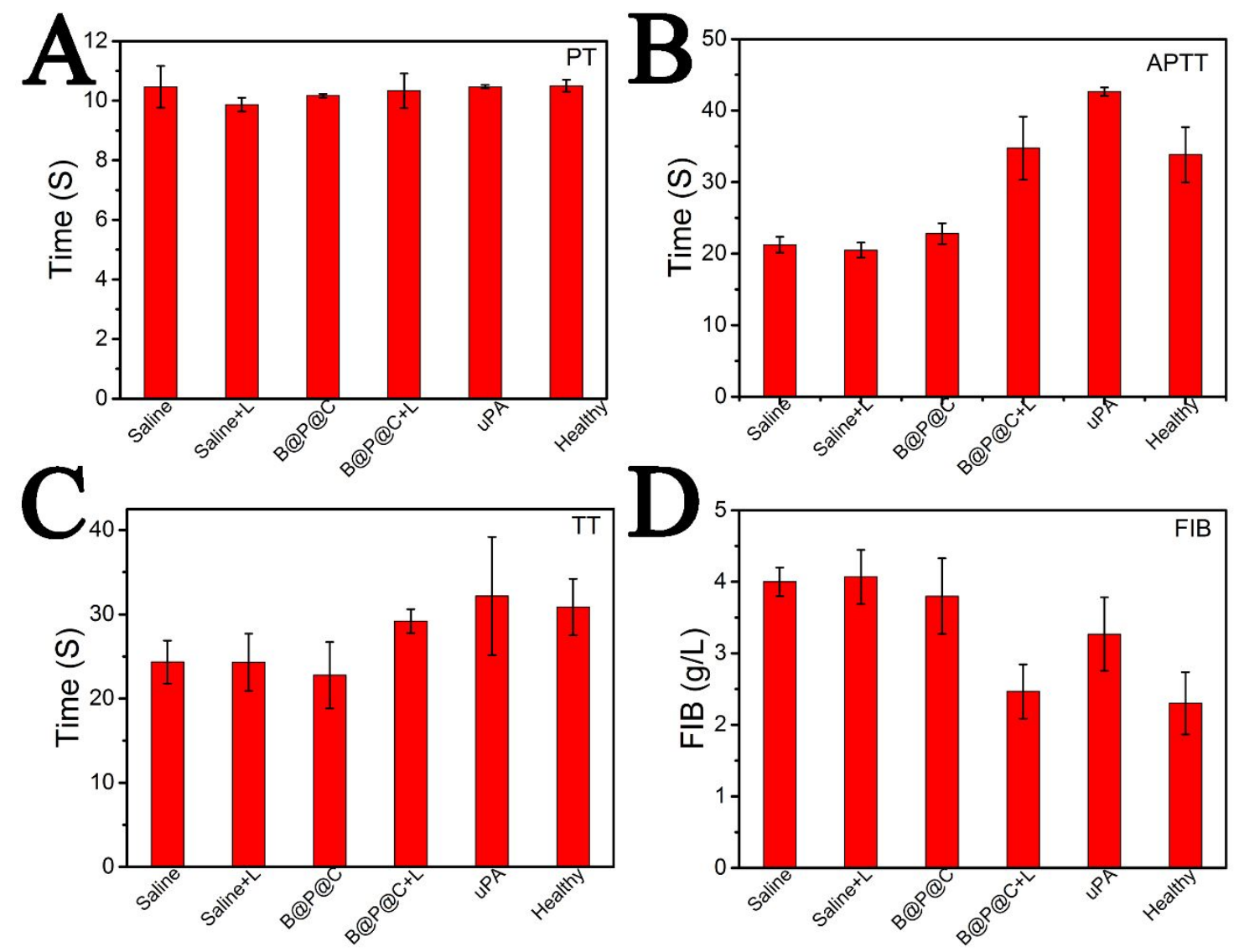

Figure S21. Thrombogenicity effects after different treatments. 

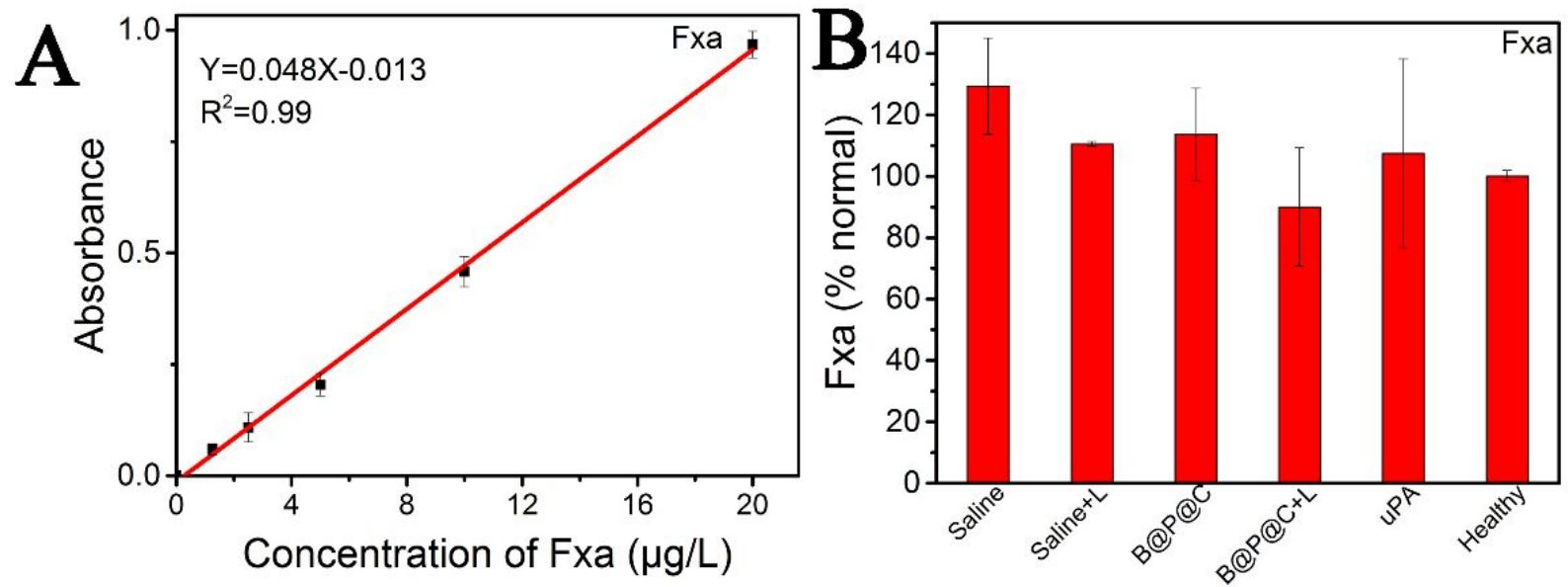

Figure S22. (A) The calibration curve of Fxa. (B) The Fxa activity after different treatments. 

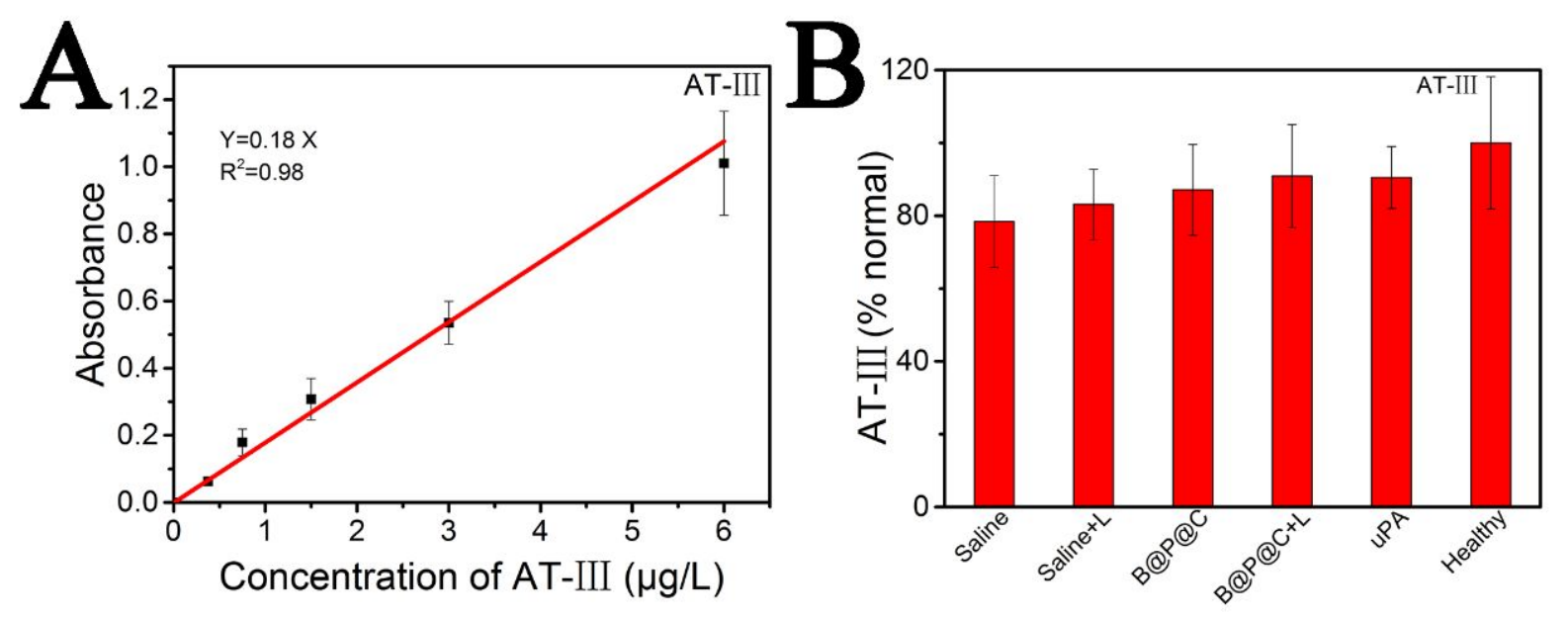

Figure S23. (A) The calibration curve of AT-Ш. (B) The Fxa activity in plasma after different treatments. 

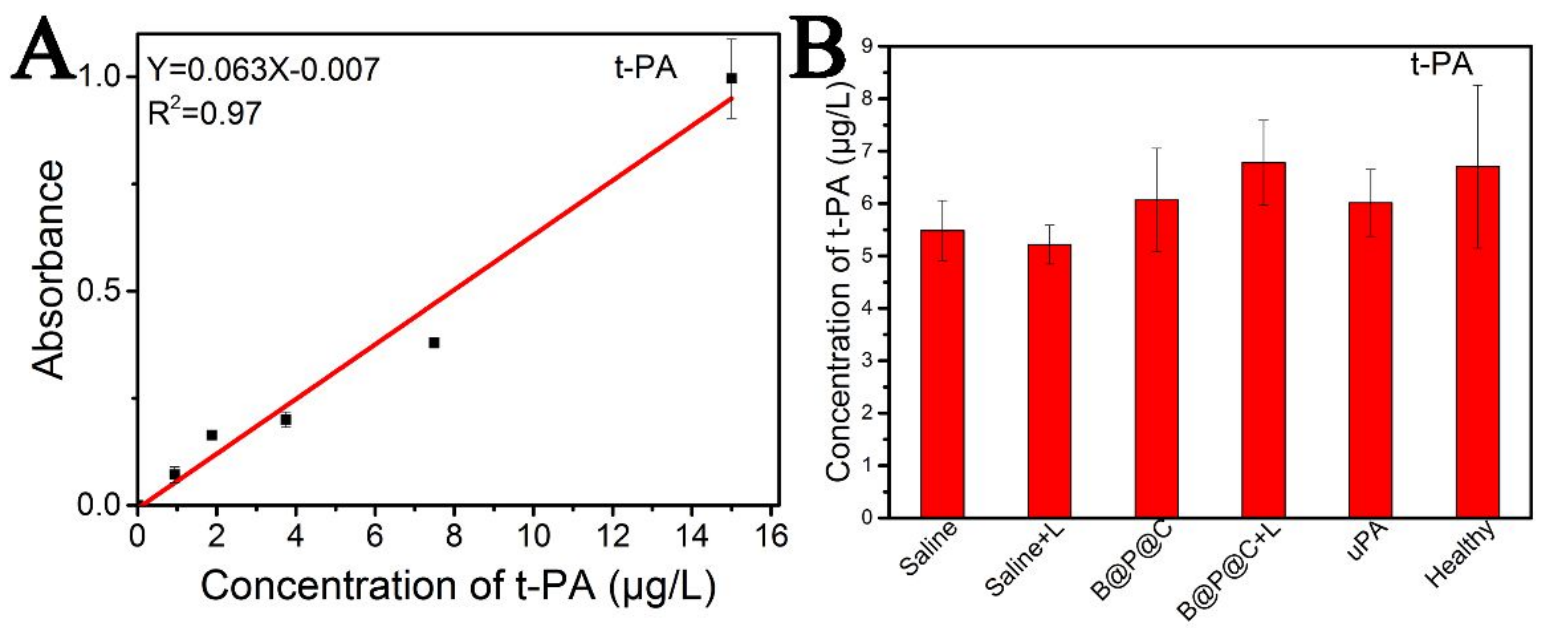

Figure S24. (A) The calibration curve of t-PA. (B) The concentration of t-PA in plasma after different treatments. 